\title{
Title
}

Assessing and providing person-centred care: variability, challenges and threats

\section{Running Head:}

Assessing and providing person-centred care

\section{Authors:}

Laurie Grealish RN $\mathrm{PhD}^{1,2}$

Associate Professor, Subacute and Aged Nursing Research

Toni Simpson RN NP ${ }^{2}$

Nurse Practitioner, Older Person

Dawn Soltau RN, NP2

Nurse Practitioner, Dementia

David Edvardsson RN, $\mathrm{PhD}^{3,4}$

Professor and Director

1. Menzies Health Institute Queensland, Griffith University

2. Gold Coast Health

3. School of Nursing and Midwifery, La Trobe University, Australia

4. Department of Nursing, Umea University, Sweden

\section{Corresponding author}

Laurie Grealish RN PhD (corresponding author)

Associate Professor, Subacute and Aged Nursing Research

Menzies Health Institute Queensland, Griffith University \& Gold Coast Health

G01, 2.05c

Griffith University, Gold Coast Campus

Parklands Drive,

SOUTHPORT 4215

Queensland, Australia

Email: l.grealish@griffith.edu.au

Phone: +61 755529558

Mob: +61 0412091968

Fax: +61 755528526

\section{Acknowledgement}

This work was undertaken as part of the Griffith University Short Term Visiting Research Fellowship program.

C. Rushton and H. Wang, both supported by the Griffith University Strategic Investment Fund, provided assistance with administration related to the study. J.Todd provided assistance with the statistical analyses in this study.

\section{Author contributions}

Study conception/design; LG, TS, DS, DE

Data collection/analysis; LG, TS, DS, DE

Drafting of manuscript; LG

Critical revisions for important intellectual content; TS, DS, DE 
Assessing and providing person-centred care of older people with cognitive impairment in acute settings: threats, variability, and challenges.

\section{ABSTRACT}

Background: Person-centred care is widely accepted in health policy as a central focus for health services. However, research studies indicate that, for nurses, the person-centred care of older people with cognitive impairment is challenging. Aim: This study aimed to compare levels of person-centred care between wards and professional groups (ENs and RNs) providing tertiary hospital care of older people with cognitive impairment.

Methods: A descriptive cross-sectional survey design, using the 15-item Personcentredness of Older People with cognitive impairment in Acute Care (POPAC) survey instrument, was undertaken.

Results: Nurses working in hospital wards of a tertiary-level health service ( $n=240$; $\mathrm{RR}=54.3 \%$ ) responded. Person-centred care was rated lower in wards with higher patient turnover compared to wards with lower patient turnover. Person-centred care was rated higher by enrolled nurses compared to registered nurses.

Discussion: Hospital context, specifically high turnover wards, present a threat to person-centred care, possibly related to the limited time available to undertake the personal care and associated conversations that can enhance nurses' knowledge of the person. ENs carry more responsibility for these tasks, possibly explaining the variability in person-centred scores between RNs and ENs. In comparison to other studies, nurses in this study had higher average scores for person-centred care, raising measurement as an important challenge in monitoring the implementation of personcentred care policy. 
Conclusion: The focus on health service efficiency appears to pose a threat to nurses' delivery of person-centred care. Further research into the variability between personcentred care of RNs and ENs, and investigation into the practices of other health disciplines would be valuable. Given the importance of person-centred care to the safety and quality of health services, the POPAC addresses the challenge of monitoring person-centred policy initiatives. However, self-report instruments should be balanced with other sources of information about practice.

KEY WORDS: person-centred, older person, cognitive impairment, dementia, acute care 


\section{SUMMARY OF RELEVANCE}

Problem or Issue

Poor health outcomes for older people with cognitive impairment in hospital are associated with limited person-centred care.

What is Already Known

The implementation of policy directives for person-centred care for older people with cognitive impairment in acute care settings is repeatedly reported as being a challenge, commonly attributed to limitations in staff knowledge of cognitive impairment generally, and dementia specifically.

What this paper adds

The nursing delivery of person-centred care is threatened in wards with high turnover. The extent to which the variability between EN and RN self-report of person-centred care may be attributed to the delivery of personal care requires further investigation. The POPAC instrument provides an easy to administer measurement for monitoring person-centred care policy initiatives but self-report needs to be balanced with other sources of evidence. 


\section{INTRODUCTION}

The percentage of people aged over 60 years is expected to rise to $21.5 \%$ of the global population, or 2.1 billion people, by 2050 (HelpAge International, 2015). Of those people aged over 60 years in 2015, the prevalence of dementia ranges from 4.6\% in Central Europe to 8.7\% in North Africa and the Middle East, with other regions in a narrower range of 5.6\% to 7.6\% (Prince, Wimo, Guerchet et al., 2015). In Australia, older people account for around $40 \%$ of hospitalisations (Australian Institute of Health and Welfare, 2015), meaning that it is increasingly important that nurses possess the skills to care for older people with dementia. In one study, almost one-third of patients in orthopaedic wards across four hospitals were found to be cognitively impaired due to dementia or delirium (Travers, Byrne, Pachana, Klein, Gray, 2012).

Cognitive impairment, commonly associated with dementia, can create challenges in communication, leading to care that may not be person-centred (Moyle, Borbasi, Wallis, Olorenshaw, Gracia, 2011). Further to this, hospitalised older people with dementia are at higher risk of hospital-acquired complications (Bail, Berry, Grealish et al., 2013), which have been deemed nurse sensitive, or attributed to missed nursing care (Bail \& Grealish, 2016). A recent review of the literature found that poor outcomes for people with cognitive impairment can be attributed to insufficient understanding of what constitutes person-centred care in the acute setting (Dewing \& Dijk, 2016).

\section{LITERATURE REVIEW}

Person-centred care has become an international standard in health care services, where including the person or consumer perspective is critical to high quality care. There is no single definition of person-centred care. In a systematic review of the 
literature on person-centred care for older adults, 15 descriptions of person-centred care were found, with 17 central principles or values (Kogan, Wilber, Mosqueda, 2016). Six domains of person-centred care emerged from the review, including holistic or whole person care, respect and value, choice, dignity, self-determination, and purposeful living (Kogan et al., 2016). Person-centred care processes, and more specifically physical care or tasks, are acknowledged as a 'way in' to meaningful relationships with patients (McCormack, Karlsson, Dewing, Lerdal, 2014). Ekman and colleagues (2011) suggest the following three clinical routines to initiate, integrate and safeguard person-centred care in clinical practice: using patient narratives to initiate a partnership, using shared decision making to integrate and consolidate the partnership, and documenting narratives to safeguard the partnership. However, in a meta-analysis of qualitative studies, nursing care processes were found to be largely ritualistic and routine, offering few opportunities to build meaningful, person-centred, relationships (McCormack et al., 2014).

When older patients have cognitive impairment, how to be person-centred becomes even more difficult for nurses. In a qualitative study, set in a Swedish acute care hospital, researchers found that nurses were unable to meet the needs of older people with cognitive impairment (Nilsson, Rasmussen, Edvardsson, 2013). One of the three significant barriers to person-centred care was working within a disease oriented and efficiency-driven organisation (Nilsson et al., 2013). Specifically, in wards with high levels of specialisation, the older person with cognitive impairment did not fit the system and policies of the unit, with care organised by efficient routines rather than patients' subjective needs (Nilsson et al., 2013).

In an efficiency-driven context, those tasks that elude clear estimation of timeeffort-value, such as person-centred psychosocial care, are commonly left undone (Ausserhofer, Zander, Busse et al., 2014). Physical care such as dressing a leg ulcer, 
the care that generally takes less time to complete, is seen as 'more acute' and privileged (Schluter, Seaton, Chaboyer, 2011). For nurses in the acute care setting, there are accepted activities and timeframes that should be followed and admission of patients who are cognitively impaired disrupt these routines (Schluter et al., 2011). Further, the contingencies and interruptions to nursing work found in wards with high turnover may lead to implicit rationing of nursing services, particularly personal care interventions (Bail \& Grealish, 2016). It is through these personal care acts that the closeness required to be person-centred has been described to emerge (Weinberg, 2006).

In the Australian setting, nurses work in teams, with bachelor-qualified registered nurses and diploma-qualified enrolled nurses. To get the work completed during a single shift, registered nurses (RN) and enrolled nurses (EN) will trade tasks to ensure the workload is evenly shared among the team (Schluter et al., 2011), with RNs carrying responsibility for technical and administrative activities and ENs carrying responsibility for more personal care activities. In an observational study of 114 nurses conducting 14,528 activities, ENs more often completed direct care activities such as hygiene, patient/family interaction, nutrition, elimination, and mobility (Chaboyer, Wallis, Duffield et al., 2008). The role of the EN in personcentred care is worthy of further exploration.

While person-centred care is valued in contemporary hospital settings, providing person-centred care to older people with cognitive impairment may be complicated by the specialist structure of tertiary hospitals that focuses on physical disease presentations and efficiency. It is timely to investigate how nurses perceive their care of older people with cognitive impairment in the acute hospital context and to explore the variance between wards, perspectives and studies. 
This study aimed to compare levels of person-centred care between wards, professional groups (ENs and RNs) providing tertiary hospital care of older people with cognitive impairment.

\section{CONTEXT AND PARTICIPANTS}

The participants included registered and enrolled nursing staff working in ten wards from two hospitals in one state health jurisdiction in Australia. The types of wards included medical ( $\mathrm{n}=6)$, medical assessment, co-located with emergency department $(n=2)$, and surgical (orthopaedic=1; urology=1). The wards typically had between 24 and 32 beds. Inclusion criteria included currently working as a registered or enrolled nurse in the selected wards and being available and willing to participate.

\section{ETHICS}

The study was conducted according to the Australian National Statement on Ethical Conduct in Human Research (2007). The health service’s Human Research Ethics Committee (HREC) provided ethical approval for the conduct of the study (14/QGC/183), with subsequent approval by the university partner HREC.

\section{METHODS}

A descriptive cross-sectional survey design was used to explore nurses’ perceived levels of person-centred care for older people with cognitive impairment. Cultural and structural elements of person-centred care were investigated, guided by the following research questions:

1. Is there a difference in perceived levels of person-centred care between nurses working in high and low turnover wards? 
2. Is there a difference in perceived levels of person-centred care between registered and enrolled nurses?

The POPAC scale

There are a few tools available in the literature for measuring person-centred care, but the majority have been developed for long-term and residential care contexts (Edvardsson \& Innes, 2010). The 'Person-centredness of Older People with cognitive impairment in Acute Care (POPAC) scale was selected due to its design for the hospital setting, published psychometric properties and ease in administration (selfreport tool). The 15-item scale has three sub-scales: using cognitive assessments and care interventions (five items); using evidence and expertise in cognition (three items); and individualising care (seven items). The POPAC scale has been found to be valid and reliable, Cronbach's alpha 0.87 for the total scale (Edvardsson, Nilsson, Fetherstonhaugh, Nay, Crowe, 2013).

The scale is focused on staff views on the extent of person-centredness and has three subscales. The first subscale, 'using cognitive assessments and care interventions’ includes assessment on admission, making environmental adjustments, diagnosing delirium, and spending more time with older people with cognitive impairment. The second, ‘using evidence and expertise in cognition’ includes items on evidence-based assessment tools, consulting specialists, and using evidence-based guidelines. The third, 'individualising care' includes using biographical information about interests to plan care, involving patient and family in care and care decisions, providing staff continuity, and evaluating care.

The scale measures the frequency with which nurses perceive person-centred practices to be undertaken in the ward. The responses to each item are provided on a six-point Likert-type scale that ranges from ‘never’ (1), 'very rarely’ (2), 'rarely’ (3), 
'frequently’ (4), 'very frequently’ (5), to 'always’ (6). Higher scores mean more person-centredness, with the exception of one item, which was reverse scored.

Demographic variables for participants, such as age, gender, professional and educational level, were included with the survey.

\section{Data collection}

A non-probability, purposive sampling technique was used. While nonprobability approaches are less likely to produce representative samples, purposive sampling allows researchers to select people who have knowledge about the issues under study (Polit \& Beck, 2012). In this study, nurses who worked in wards with a higher percentage of patients aged 65 years and older were included.

Nurses were invited to complete the survey during regularly scheduled ward meetings. A research assistant distributed and collected the surveys over a four-week period. Completed questionnaires were deposited in a sealed envelope in a folder held in the Nursing Unit Manager or Clinical Facilitator office and collected each week. No personally identifiable information was collected with the questionnaires and participants were guaranteed confidentiality. Data were collected between July and August 2015.

\section{Statistical analyses}

Between-group comparative analyses were conducted using item score ttests with a p-value of $<0.05$ considered as being statistically significant. Wards with higher patient turnover (medical assessment and surgical wards) were hypothesised to possibly present less time for person centred care delivery compared to wards with lower patient turnover. Independent samples $t$-tests were conducted to compare the mean POPAC responses of staff between wards with higher and lower patient 
turnover (medical wards compared to short-stay wards) on each of the three subscales; Individualising Care, Using Cognitive Assessments and Care Interventions and Using Evidence and Expertise in Cognition; and the total score.

Due to the differences in scope of practice and closeness to fundamental nursing care provision, it was hypothesised that ENs possibly would rate the levels of person-centred care as being different compared to RNs. The non-parametric technique Mann-Whitney $U$ was used to compare each group, due to the unequal sample sizes of the RN and EN group.

\section{RESULTS}

There were 240 questionnaires returned from a sample of 442, providing a 54.3\% response rate. Most respondents were female between the ages of 20 to 29 years. Sixteen participants had a post-graduate qualification in geriatrics. Sample characteristics are provided in Table 1.

Please insert Table 1 about here.

The comparison of perceptions of staff in wards with higher and lower patient turnover showed that the staff on the medical wards (lower turnover) rated themselves significantly higher on each of the subscales and the total score compared to those on the shorter stay (high turnover) wards (see Table 2).

Please insert Table 2 about here.

When comparing the qualification subgroups, ENs’ perceptions of personcentred care were significantly higher on Individualising Care $(p=.003, r=.19)$; 
Using Evidence in Expertise in Cognition $(p=.002, r=.20)$ and total scores $(p=.02$, $r=.16)$ compared to RNs. There was no significant difference between the groups on Using Cognitive Assessments and Care Interventions $(p=.10)$. The descriptive statistics are presented in Table 3.

Please insert Table 3 about here

\section{DISCUSSION}

Person-centred practices for people with cognitive impairment have been described as consistent with practices considered as essential nursing care practices, such as talking with patients, educating patients, and developing individual plans of care (Australian Commission on Safety and Quality in Health Care, 2014). The challenges in delivering person-centred care for older people with cognitive impairment in contemporary hospitals has been attributed, at least partly, to the specialist structure that focuses on physical disease presentations and efficiency (Nilsson et al., 2013).

For the purpose of analysis in this study, it was hypothesised that the focus on efficiency and bed use was higher in medical assessment and surgical units than in medical units. Nurses working in those areas with a higher focus on efficiency ranked person-centredness for older people with cognitive impairment as lower than nurses working in medical wards with lower patient turnover. This can be interpreted to indicate that nurses working in highly specialised units perceive challenges towards providing person-centred care for people who are cognitively impaired (Nilsson et al., 2013; Schluter et al., 2011). In an environment of efficiency, it may be difficult to perceive and sustain person-centred care. Further exploration of the variability in person-centred care for older people with cognitive impairment between hospital wards, acuity and efficiency would be valuable. 
The results also indicate that ENs consistently rated the level of personcentredness higher compared to RNs in this sample. One possible interpretation of this results is that ENs being more actively involved in the essential nursing care aspects of the caring process, perceive the opportunities for and actual provision of person-centred care as being higher (McCormack \& McCance, 2006). Previous studies have shown that in tertiary hospitals, ENs are closer to the essential care and activities of daily life of patients generally (Chaboyer et al., 2008) and with older people with cognitive impairment specifically (Nilsson, Lindkvist, Rasmussen, Edvardsson, 2012). However, with this also comes the risk that essential care may be ritualised and not person-centred (McCormack et al., 2014). The findings in this study can be interpreted to suggest that the role of ENs may be fundamentally important in perceiving and/or providing person-centred care to older people with cognitive impairment in tertiary hospitals. However, further research to explain this variability would be valuable to extend the understanding of person-centred care in relation to scope of practice and the 'body work' of various caring professions.

In this health service, ENs constituted around 30\% of the nursing population. How the EN role can be further enhanced to promote person-centred care in hospitals, and in particular medical assessment and surgical units, seems worthy of exploration. Further inquiry into RN and EN participation in person-centred care activities could potentially include interviews with both groups of nurses as well as participant observations to learn more about the extent to which their perceptions actually correspond to their observable practice and to the experiences of older patients and family members themselves.

The average ratings for person-centred care in this sample were compared to those in other studies, conducted with nurses in Australia (Edvardsson et al., 2013) and with nurses and physicians in Sweden (Nilsson et al., 2013). The participants in 
this study reported much higher levels of person-centred care overall ( $x=4.43$, $\mathrm{SD}=0.74)$, compared with Australia $(\mathrm{x}=3.63, \mathrm{SD}=0.99)$ and Sweden $(\mathrm{x}=3.10$, $\mathrm{SD}=1.14)$. The higher ratings on person-centred care in this sample was surprising. However, the Swedish sample was different to this study sample by including physicians and so comparison need to be interpreted with caution. However, this finding raises the risk of social desirability bias (van de Mortel, 2008) or politically correct response bias (Adams, Soumeri, Lomas, Ross-Degnan, 1999; Donaldson \& Grant-Vallone, 2002) when using self-report instruments.

The contemporary health services context of audit, performance measurement, individual accountability, standards and comparison, has led to a range of self-report instruments to support internal monitoring of performance. However, measurement of value-laden concepts such as person-centred care may be complicated by individual desires to maximise their positions vis-à-vis desirable practice, professional performance and markets (Feakins, 2010). In this case, it is possible that for staff to describe their collective practices as not being highly person-centred would mean a non-strategic positioning in relation to performance indicators and market expectations. This raises methodological issues about how to study personcentredness of care with accuracy, trustworthiness and rigour. Further research that connects participant observations and stakeholder experiences to self-report scores could confirm or reject the extent to which self-reporting of person-centred care corresponds to observed practice and practice as perceived by the recipients of care. The self-report limitations and associated risk of bias suggest that the findings should be considered cautiously.

\section{Limitations}


There are some limitations to this study. The sample selection was based on convenience, which limits generalizability of the findings. It is possible that those nurses who did not participate hold different views on the care of older people with cognitive impairment. Average length of stay was not collected which limits investigation of an association between increased length of stay and opportunities for staff to provide person-centred care with patients and families. This would be useful to explore in future studies.

\section{CONCLUSIONS}

In this study, factors such as high patient turnover and differing professional responsibilities appear to influence nurses’ perceptions of person-centred practice. Exploratory research into the mechanics of the relationship between person-centred care for older people with cognitive impairment and patient turnover is required. To gather improved insights into the variability between $\mathrm{RN}$ and EN perceptions of person-centred care, ethnographic research, where practice is observed and checked against nurse perceptions, is recommended. To monitor the implementation of best practice person-centred care, observations of practice, as well as collecting information about patient and carer experiences, can be used to triangulate the findings of the POPAC scale and draw conclusions about the quality of personcentred care. The development of an instrument to measure patient or carer experiences of person-centred care would provide another useful indicator for policy implementation. 


\section{REFERENCES}

Adams, A.S., Soumeri, S.B., Lomas, J., Ross-Degnan, G. (1999). Evidence of selfreport bias in assessing adherence to guidelines. Int J Qual Health Care 11(3), 18792.

Ausserhofer, D., Zander, B., Busse, R., Schubert, M., De Geest, S., Rafferty, A.,M., Ball, J., Scott, A., Kinnunen, J., Heinen, M., Sjetne, I.S., Moreno-Casbas, T., Kozka, M., Lindqvist, R., Diomidous, M., Buryneel, L., Sermeus, W., Aiken, L.H., Schwendimann, R., on behalf of the RN 4CAST Consortium. (2014). Prevalence, patterns and predictors of nursing care left undone in European hospitals: results from the multicountry cross-sectional RN4CAST study. BMJ Quality \& Safety 23 (2), 12635 .

Australian Commission on Safety and Quality in Health Care. (2014). A better way to care: Safe and high quality care for patients with cognitive impairment (dementia and delirium) in hospital - Actions for clinicians. Sydney; ACSQHC.

Australian Institute of Health and Welfare. (2015). Admitted patient care 2013-14: Australian hospital statistics. AIHW, Canberra.

Bail, K., Berry, H., Grealish, L., Draper, B., Karmel, R., Gibson, D., Peut, A. (2013) Potentially preventable complications of urinary tract infections, pressure areas, pneumonia, and delirium in hospitalised dementia patients: Retrospective cohort study. BMJ Open, 3:e002770. doi:10.1136/bmjopen-2013- 002770

Bail K. \& Grealish L. (2016). 'Failure to Maintain': A theoretical proposition for a new quality indicator of nurse care rationing for complex older people in hospital. International Journal of Nursing Studies. 63, 146-161. doi:

10.1016/j.ijnurstu.2016.08.001

Chaboyer, W., Wallis, M., Duffield, C., Courtney, M., Seaton, P., Holzhauser, K., S... Bost, N. (2008). A comparison of activities undertaken by enrolled and registered nurses on medical wards in Australia: an observational study. Int J Nurs St 45(9), 1274-84.

Dewing, J. \& Dijk, S. (2016) What is the current state of care for older people with dementia in general hospitals? A literature review. Dementia 15(1), 106-124.

Donaldson, S.I. \& Grant-Vallone, E.J. (2002). Understanding self-report bias in organizational research. Journal of Business and Psychology 17(2), 245-60.

Edvardsson, D. \& Innes, A. (2010). Measuring person-centred care: a critical comparative review of published tools. The Gerontologist 50(6), 834-846. DOI: 10.1093/geront/gnq047

Edvardsson, D., Nilsson, A., Fetherstonhaugh, D., Nay, R., Crowe, S. (2013). The person-centred care of older people with cognitive impairment scale. Journal of Nursing Management 21(1), 79-86.

Edvardsson, D., Winblad, B., Sandman, P.O. (2008). Person-centred care of people with severe Alzheimer's Disease: current status and ways forward. Lancet Neurology 7(4), 362-67. 
Ekman, I., Swedberg, K., Taft, C., Lindseth, A., Norberg, A., Brink, E., Carlsson, J., Dahlin-Ivanoff, S., Johansson, I., Kjellgren, K., Liden, E., Ohlen, J., Olsson, L., Rosen, H., Rydmark, M., Sunnerhagen, K.S. (2011). Person-centered care - ready for prime time. Eur J Cardiovasc Nurs 10(4), 248-51. doi:

10.1016/j.ejcnurse.2011.06.008

Feakins, M. (2010). Local experiments with global certificates: how Russian software testers are inventing themselves as a profession. In V. Higgins \& W. Larner (eds), Calculating the Social: Standards and the Reconfiguration of Governing. Palgrave McMillan: UK, pp. 151-66.

HelpAge International. (2015). Global AgeWatch Index 2015: Insight report. HelpAge: London. Available from http://www.helpage.org/globalagewatch/reports/global-agewatch-index-2015-insight-report-summary-andmethodology/, downloaded 14 June 2016.

Kogan, A.C., Wilber, K. \& Mosqueda, L. (2016). Person-centred care for older adults with chronic conditions and functional impairment: a systematic literature review. $J$ Am Geriatr Soc 64(1), e1-e7. DOI: 10.1111/jgs.13873

McCormack, B., Karlsson, B., Dewing, J., Lerdal, A. (2014). Exploring personcentredness: a qualitative meta-synthesis of four studies. Scand J Caring Sci 24(3), 620-634. DOI: 10.1111/j.1471-6712.2010.00814.x.

McCormack, B. \& McCance, T.V. (2006). Development of a framework for personcentred nursing. J Adv Nurs 56(5), 472-479.

Moyle, W., Borbasi, S., Wallis, M., Olorenshaw, R., Gracia, N. (2011). Acute care management of older people with dementia: a qualitative perspective. Journal of Clinical Nursing 20 (3-4), 420-428.

National Statement on Ethical Conduct in Human Research. (2007; Updated May 2015). The National Health and Medical Research Council, the Australian Research Council and the Australian Vice-Chancellors' Committee. Commonwealth of Australia, Canberra.

Nilsson, A., Lindkvist, M., Rasmussen, B.H. \& Edvardsson, D. (2012). Staff attitudes towards older patients with cognitive impairment: need for improvements in acute care. Journal of Nursing Management 20(5), 640-47.

Nilsson, A., Lindkvist, M., Rasmussen, B.H. \& Edvardsson, D. (2013). Measuring levels of person-centredness in acute care of older people with cognitive impairment: evaluation of the POPAC scale. BMC Health Services Research 13:327.

Nilsson A., Rasmussen B. \& Edvardsson D. (2013). Falling Behind: a substantive theory of care for older people with cognitive impairment in acute settings. Journal of Clinical Nursing 22(11-12), 1682-91.

Polit, D.F, Tatano Beck, C. (2012). Nursing Research: Generating and Assessing Evidence for Nursing Practice, 9e. Lippincott Williams \& Wilkins: Philadelphia. 
Prince, M., Wimo, A., Guerchet, M., Ali, G., Wu, Y. \& Prina, M. (2015). World Alzheimer Report 2015. The global impact of dementia: an analysis of prevalence, incidence, cost and trends. Alzheimer's Disease International, London.

Schluter , J., Seaton, P. \& Chaboyer, W. (2011). Understanding nursing scope of practice: a qualitative study. Int J Nurs St 48(10), 1211-22.

Travers, C., Byrne, G., Pachana, N., Klein, K. \& Gray, L. (2012). Prospective observational study of dementia and delirium in the acute hospital setting. Internal Medicine Journal 43(3), 262-69.

van de Mortel, T.F. (2008). Faking it: social desirability response bias in self-report research. Australian Journal of Advanced Nursing 25(4), 40-48.

Weinberg, D. (2006). When little things are big things: the importance of relationships for nurses' professional practice. In S. Nelson \& S. Gordon (eds). The Complexities of Care: Nursing Reconsidered. Cornell University Press, New York. 
Table 1. Current Sample Characteristics

$$
N(\%)
$$

Gender $(n=238)$

Women

$210(88.2)$

Men

28 (11.8)

Qualification $(n=240)$

Registered Nurses

197 (82.1)

Enrolled nurses

$42(17.5)$

Other

$1(0.4)$

Age Group ( $n=239)$

20-29 years

92 (38.5)

30-39 years

45 (18.8)

40-49 years

$54(22.6)$

50-59 years

$38(15.9)$

$60+$ years

$10(4.2)$

\section{Post-graduate qualification in}

gerontology $(n=239)$

No

Yes

$16(6.7)$ 
Table 2. Means, Standard Deviations (SD) and t-tests for the Subscale and Total Scores: Turnover

\begin{tabular}{|c|c|c|c|c|}
\hline & Medical & MAU/surgical & $t$-test & Cohen's $d$ \\
\hline \multicolumn{5}{|c|}{ Individualising Care } \\
\hline$M(S D)$ & $4.55(.66)$ & $4.22(.82)$ & $-3.44^{\mathrm{a}}$ & .47 \\
\hline$n$ & 146 & 88 & & \\
\hline \multicolumn{5}{|c|}{ Using Cognitive } \\
\hline \multicolumn{5}{|c|}{ Assessments and Care } \\
\hline Interventions & $4.65(.60)$ & $4.343(.76)$ & $-2.30^{c}$ & .30 \\
\hline$M(S D)$ & 140 & 83 & & \\
\hline \multicolumn{5}{|l|}{$n$} \\
\hline \multicolumn{5}{|c|}{ Using Evidence and } \\
\hline \multicolumn{5}{|c|}{ Expertise in Cognition } \\
\hline$M(S D)$ & $4.64(.91)$ & $4.23(1.07)$ & $-3.05^{b}$ & .40 \\
\hline$n$ & 145 & 88 & & \\
\hline \multicolumn{5}{|l|}{ Total Score } \\
\hline$M(S D)$ & $4.60(.54)$ & $4.28(.69)$ & $-3.84^{\mathrm{a}}$ & .50 \\
\hline$n$ & 136 & 78 & & \\
\hline
\end{tabular}


Table 3. Medians and Interquartile Ranges (IQR) for the Subscale and Total Scores for the Registered Nurse and Enrolled Nurse Qualification Subgroups

\begin{tabular}{|c|c|c|}
\hline & Registered Nurses & Enrolled Nurses \\
\hline \multicolumn{3}{|c|}{ Individualising Care } \\
\hline$M d n(I Q R)$ & $4.4(3.9-4.9)$ & $4.6(4.2-5.3)$ \\
\hline$n$ & 193 & 41 \\
\hline \multicolumn{3}{|c|}{ Using Cognitive Assessments } \\
\hline \multicolumn{3}{|c|}{ and Care Interventions } \\
\hline$M d n(I Q R)$ & $4.6(4.2-5.0)$ & $4.8(4.2-5.2)$ \\
\hline$n$ & 186 & 35 \\
\hline \multicolumn{3}{|c|}{ Using Evidence and Expertise } \\
\hline \multicolumn{3}{|l|}{ in Cognition } \\
\hline$M d n(I Q R)$ & $4.3(3.7-5.0)$ & $5.0(4.3-5.6)$ \\
\hline$n$ & 192 & 41 \\
\hline \multicolumn{3}{|l|}{ Total Score } \\
\hline$M d n(I Q R)$ & $4.5(4.0-4.9)$ & $4.8(4.4-5.0)$ \\
\hline$n$ & 178 & 35 \\
\hline
\end{tabular}


